\title{
A global-scale overview of precipitation-deficit flash droughts
}

\author{
Natalia Limones * \\ University of Seville, Seville, Spain
}

\begin{abstract}
Article history:
Received 23 March 2021

Revised 15 September 2021

Accepted 16 September 2021
\end{abstract}

Keywords:

Precipitation extremes, Flash drought, Spatiotemporal patterns, Drought indexes, High-resolution gridded datasets

Citation:

Limones, N., 2021: A global-scale overview of precipitation-deficit flash droughts. Terr. Atmos. Ocean. Sci., 32, 597-611, doi: 10.3319/ TAO.2021.09.16.01

\begin{abstract}
Flash droughts are defined as fast and intense dryings of the land system. In these episodes, declines in precipitation deficits are often accompanied by rapid intensifications of evaporative demand, leading to sharp soil moisture decreases and noticeable agricultural and environmental impacts. This research presents a straightforward framework for global historical characterization of precipitation-deficit-related flash droughts, examining the extent to which this type of hazard can be described using only pentad rainfall data. The Drought Exceedance Probability Index was applied to global gridded high-resolution rainfall data for 1979 - 2020. Sharp upsurges in the pentad index series were detected and counted to analyze the occurrence of precipitation-deficit flash droughts. The precipitation characteristics associated to flash drought incidence were explored to learn if some rainfall regimes or times of the year are more prone to the phenomenon, which could help societies become more prepared for the risk. It was observed that climates with marked inter-annual and intra-annual rainfall variability record more flash droughts, especially when that variability is significant during the local wet seasons. This is the case of regions with erratic rainfall generation mechanisms such as Mediterranean climates or monsoon climates. The episodes mainly occur during what is expected to be the humid time of the year, when they can produce greater impact. The methodology used was able to detect the most intense events described in previous studies that used variables associated to soil moisture dryness, confirming the role of acute precipitation deficits in triggering them.
\end{abstract}

\section{INTRODUCTION}

\subsection{Background and State of the Art Regarding Flash Droughts}

Drought is defined by the World Meteorological Organization in the Integrated Drought Management Program Glossary as a "prolonged absence or marked deficiency of precipitation or a period of abnormally dry weather, sufficiently prolonged for the lack of precipitation to cause a hydrological imbalance". According to that definition, droughts can occur anywhere and can generate significant impacts due to disruption of the usual climatic, moisture and water availability rhythms. Due to these significant impacts on agriculture, ecology, environment and economy, it is of great significance to continue analyzing the spatiotemporal behaviour and change trend of drought occurrence for disaster prevention and mitigation (Yan et al. 2021).

\footnotetext{
* Corresponding author

E-mail:natalialr@us.es
}

However, activities and the environment are not just disrupted by prolonged drought periods (Otkin et al. 2018). Anomalously rapid intensification of droughts has also proven detrimental, especially for vegetation when occurring during the respective growing season ( $\mathrm{Li}$ et al. 2020a). Such droughts are known as flash droughts and are gaining more attention in the years of publication of this study.

Related research published to date has analyzed the evolution at high temporal resolution of one or several indexes based on hydrometeorological variables such as precipitation and soil moisture, though also evapotranspiration, temperatures, and other meteorological parameters, in order to identify and describe flash drought (FD) events in specific areas (Mo and Lettenmaier 2015, 2016; Wang et al. 2016). Specifically, the phenomenon has been characterized by applying straightforward calculations that depict the 
rapid decline of the variables mentioned above (Ford and Labosier 2017; Koster et al. 2019) or of indications such as their anomalies with respect to normal values (Zhang et al. 2017; Yuan et al. 2018; Li et al. 2020a, b), the Evaporative Stress Index (Otkin et al. 2013, 2018; Christian et al. 2019), the Standardized Precipitation-Evapotranspiration Index (SPEI) (Noguera et al. 2020) or the Evaporative Demand Drought Index, based on potential evapotranspiration data (Pendergrass et al. 2020).

Most emphasis has been on FDs' impacts on soil moisture depletion and the indexes used are therefore meant to track that aspect. The effects of such droughts on the vegetation itself, runoff, groundwater or surface storage have received less attention, although propagation to those stages of the hydrological cycle is usually more sensitive to prolonged deficits or to the clustering of several consecutive droughts; basin characteristics also make it harder to identify direct connections (Van Loon 2013).

The United States National Integrated Drought Information System states in its website that contrary to conventional droughts, in which precipitation deficit is the essential feature, FDs usually include abnormally high temperatures and evapotranspiration rates. Researchers have accordingly defined two main categories of FDs: precipitation-deficit FDs and heat-wave FDs, though they are not always analyzed separately. A heat-wave FD caused by high temperature may entail an increase in evapotranspiration and soil moisture depletion over a short period. A precipitationdeficit FD is due to a severe precipitation shortfall which may be accompanied by a decrease in evapotranspiration and rising temperature (Mo and Lettenmaier 2016; Zhang et al. 2017; Wang and Yuan, 2018; Liu et al. 2020).

Several studies have focused on defining how far deficits must drop for a drought to be considered a flash drought. The definition of Mo and Lettenmaier (2016) indicated a 5 -day period of soil moisture below the $40^{\text {th }}$ percentile; that threshold was employed and adapted by Zhang et al. (2017) and Yuan et al. (2018), who also used abrupt percentile declines and the existence of evapotranspiration and precipitation anomalies to refine the characterization of events. Ford and Labosier (2017) described an FD as soil moisture declining from above the $40^{\text {th }}$ to below the $20^{\text {th }}$ percentile over a 20-day period, as those values have proven critical for the generation of environmental impacts (Svoboda et al. 2002).

In all the aforementioned efforts, the authors agree on two essential aspects for distinguishing FDs: the episodes are (1) beyond a certain rate (speed) of intensification and (2) exceed a well-defined deficit threshold in order to be classified as droughts.

Most published research has been applied to regional or country case studies. For example, a rapid decline in soil moisture is used to identify and characterize FDs in southern Africa in 2015 and 2016 (Yuan et al. 2018). Wang et al. (2016) examined long-term variability of FDs in China.
Zhang et al. (2017) analyzed FD features in the Gan River Basin, linking them to phenological cycles for the period 1961 - 2013. The initial assessments of Mo and Lettenmaier (2016) opened a series of studies by them and other authors regarding types of FDs and the challenges they pose in the United States (US).

The first quasi-global characterization approach appeared in Koster et al. (2019), which used soil moisture reanalysis data to define FD events, the ultimate purpose being to assess the contribution of evapotranspiration and precipitation anomalies to their development.

Some research work has gone beyond characterization, aiming to improve FD early warning and prediction capacity based on daily data. Li et al. (2020a) used meteorological and soil moisture data at this timescale to characterize intensification rates of the phenomenon in China's Pearl River Basin, defining the respective typical time and space dynamic propagation patterns. Mo and Lettenmaier (2016) followed a similar approach with modelled data in the US. In the same country, Otkin et al. (2018) and the National Weather Service conducted studies about the development and evolution of FD events, intending to predict their onset in sub-seasonal timescales.

In sum, the published research examples have used moderate to high data demand frameworks which allow for accurate interpretation of FD events from local to regional scale.

\subsection{Research Rationale and Objectives}

Global-scale spatiotemporal patterns and proneness to experiencing FDs have not been sufficiently studied, beyond the aforementioned efforts by Koster et al. (2019). This research was inspired by the results of that study, which held that precipitation deficit played a relevant role in generating sudden soil moisture declines, and intends to produce a straightforward framework for historical characterization of precipitation-deficit-related FD events at global scale, and to present the results of that characterization. This document hence analyzes how the precipitation-driven phenomenon behaves, without the involvement of other processes and elements of the hydrological system, also considering broader availability and accuracy of the data compared to other variables.

The Drought Exceedance Probability Index (DEPI) is used for this analysis due to its computational simplicity, since it only requires rainfall data to be calculated, and because it shows a great ability to reflect the onset, end, intensity, and actual duration of the meteorological drought (Limones et al. 2020). The time series of the DEPI index are examined to determine how many FDs have occurred in all land domains of the world (except deserts, namely those pixels recording less than 250 millimeters of annual precipitation, which were masked) and when. 
Furthermore, the rainfall conditions associated to FD incidence are explored to ascertain whether some regions and regimes are more prone to the phenomenon. The frequency of events within a year will be compared to local rainfall schedules and expected precipitation peaks to obtain a sense of their potential impact on vegetation.

The last part of the paper makes a global-scale assessment of the temporal evolution and trends in FD occurrence.

\section{MATERIALS AND METHODS}

\subsection{Flash Drought Identification}

This research focuses on characterizing precipitationdeficit flash droughts, understood and measured here simply as intense and fast declines in precipitation deficits.

\subsubsection{Using a Simple Framework Based on Precipitation Values}

Even though previous studies do not consider that abrupt rainfall deficits anticipate a rapid decline in the more complex indexes used to define FDs (combining precipitation with evapotranspiration and often other variables regarding soil moisture), it has been confirmed that a sudden drop in precipitation values (measured exclusively by observing rainfall indexes) occurs at the onset time of their identified FDs (Ford and Labosier 2017; Chen et al. 2019; $\mathrm{Li}$ et al. 2020a). This means that the abrupt decline in rainfall drought indexes is coupled with rapid impacts on soil (Koster et al. 2019) and vegetation health, even if there are other participating or prevailing parameters.

It may be especially interesting to evaluate whether the method presented is sufficient to reveal what have been defined as precipitation or water deficit driven FDs (Mo and Lettenmaier 2016). However, the same research papers also define what are called heat-driven FDs, which occur when the acute precipitation deficit combines with other extreme weather anomalies that augment evaporative demand. In such cases, the soil suffers more severe moisture depletion; it is important to confirm whether these events are captured when following our characterization framework.

On the other hand, droughts measured by precipitation are also fully natural, upstream phenomena not affected by water, land-use or soil management, which are included in some of the variables participating in other FD characterization frameworks.

Apart from its central role in drought generation, precipitation is almost always the variable with the highest temporal variability of all potential participants in a drought index, which entails that temperature or evapotranspiration have a more moderate responsibility regarding drought detection from a statistical standpoint (Vicente-Serrano et al. 2010; Asadi Zarch et al. 2011).

\subsubsection{DEPI Drought Index Calculation on Pentad Precipitation Data}

The DEPI is a meteorological drought index based on the calculation of cumulative rainfall anomalies (Limones et al. 2020) in a manner similar to the Standardized Precipitation Index (SPI) of McKee (McKee et al. 1995) or the derivative SPEI (Vicente-Serrano et al. 2010). However, each DEPI score represents the empirical probability of exceedance of the drought level experienced in that particular time unit (originally months).

For this paper, the DEPI index is simply applied to pentad precipitation data.

The index is calculated by means of the following successive stages (Limones et al. 2020).

In the first stage, the rainfall anomalies of each pentad of the series (AP) are calculated using the expression:

$A P_{i}=P_{i}-P_{M E D_{i}}$

Where:

$P_{i}=$ Precipitation of the pentad $i$

$P_{M E D_{i}}=$ Median precipitation of the pentad $i$ for the whole study period

In the second stage, cumulative rainfall anomalies are calculated from the first pentad of the series on, simply adding the sum of the previous anomalies to the new one $\left(A P_{i}\right)$. However, anytime a negative pentad anomaly $\left(A P_{i}<0\right)$ is found after a positive accumulation of anomalies, the accumulation is restarted in that particular pentad (namely, the cumulative rainfall anomaly of that pentad $i$ becomes equal to that negative $A P_{i}$, regardless of the amount accrued until the previous pentad). After that restart, the addition of anomalies continues pentad by pentad, and may become positive again after successive accumulations.

The methodology is a constant addition of excesses that ends whenever there is a negative anomaly, in order to give it importance.

Consequently, the calculation of this second phase is:

$$
A P A c_{1}=A P_{1} \quad A P A c_{i}=\sum_{j=r}^{i} A P_{i} s i \quad i>1
$$

Where:

$A P A c_{i}=$ Rainfall cumulative anomaly of the pentad $i$;

$r=$ the value marking the start of the dry sequence and follows the expression

$r=\max \left\{k: 1 \leq k \leq i, A P_{k}<0, A P A c_{k-1} \geq 0\right\}$,

Note that if $A P_{i}<0 \mathrm{y} A P A c_{i-1} \geq 0$, then $r=i$ and as a result $A P A c_{i}=A P_{i}$, marking the beginning of a new dry sequence.

Finally, in the third stage it is necessary to sort the pentad series of cumulative rainfall anomalies calculated in the 
previous stage and to compute their empirical probability of exceedance, using the plotting positions method designed by Weibull:

Pexced $A P A c_{i}=$ DEPI $i=\mathrm{M} A P A c_{i} /(\mathrm{n}+1)$

\section{Where:}

Pexced $A P A c_{i}=$ empirical probability of exceedance of the cumulative anomaly of pentad $i$, namely, the DEPI of the pentad $i$.

$\mathrm{M} A P A c_{i}=$ position of the rainfall cumulative anomaly of the pentad $i$ in the sorted series, from lowest to highest cumulative anomalies, being:

$\mathrm{M}=1$ the largest negative cumulative anomaly or largest observed deficit;

$\mathrm{n}=$ total number of pentads in the series.

Consequently, the DEPI for each pentad is literally the probability of exceedance attributable to its cumulative rainfall anomaly, computed as described above. DEPI values below 0.5 indicate bulk accumulation of negative anomalies, less likely to be surpassed as they approach DEPI 0 , and are consequently considered droughts.

For an exercise of global FD characterization like that intended by this research, the straightforward and unambiguous identification of historical dry sequences obtained from a single calculation in three stages of the DEPI index is easier to interpret than the series generated with multi-scale indexes like the SPI or SPEI, where important aspects like drought onset or intensity largely depend on the accumulation scale.

Once the pentad time series of raw precipitation are converted into series of pentad DEPI values from 1979 to 2020 , FDs need to be identified within them.

Following the Ford and Labosier (2017) thresholds and logic, adopted with minor changes by Zhang et al. (2017), Yuan et al. (2018), and Liu et al. (2020), among others, the criteria selected to register the start of an FD in a particular pentad $i$ of the series were:

(1) The DEPI of the previous pentad $(i-1)$ was above the value 0.4 (it is the $40^{\text {th }}$ percentile or an empirical probability of exceedance of the current level of drought of 0.4), namely, the previous pentad was either normal or only in a situation of very mild drought (Limones et al. 2020);

(2) In the considered pentad $i$, the DEPI values dropped below 0.2 probability of exceedance, suddenly entering moderate drought levels.

Every time those conditions appear in a series, a new FD is counted, even if they are only separated by one wet pentad, which is a virtually nonexistent situation in the series actually used.

We recommend to consult Limones et al. (2020) for examining their test of the usefulness of the DEPI index for several climates of the Earth.
Thanks to the use of the median for the DEPI formulation, the series will always have half of the months marked as wet sequences (DEPI $>0.5$ ) and half of the months marked as droughts (DEPI $<0.5$ ), with the median value of the cumulative anomalies as the tipping point between the two. This means that some negative cumulative anomalies will not be marked as droughts if they are not below the median, because they will not be considered exceptionally bulky deficits. Therefore, finding a drought value (DEPI < 0.5 ) happens in just half of the series, but to find a jump from 0.4 to below 0.2 is quite exceptional. If such situations take place they deserve to be marked as FD.

\subsection{Data}

The daily precipitation values used to calculate the pentad sums and for the rest of the precipitation statistics are obtained from the CPC Global Unified Gauge-Based Analysis of Daily Precipitation dataset (freely available at ftp://ftp.cdc.noaa.gov/Datasets/cpc global precip/). It is a widely used climate dataset on a $0.5^{\circ}$ latitude by $0.5^{\circ}$ longitude grid over all land domains, prepared by interpolation of the values of weather station observations. It covers the period 1979 - 2020 at daily scale (Chen et al. 2008). The full extent of the precipitation dataset was used for the FD analysis, both spatially (the entire globe, except desert areas) and temporally (all days from 1979 to 2020). The CPC datasets covers such a long timespan at high temporal and spatial resolution that it permits significant historical characterization of FDs. As explained in the CPC database documentation, the dataset values were subject to extensive quality control and homogenization processes.

\section{RESULTS: GLOBAL CHARACTERIZATION OF FLASH DROUGHTS}

\subsection{Global Distribution of Flash Drought Occurrence}

Figure 1 presents a grid with the total number of FDs from 1979 to 2020, showing the areas where the frequency of occurrence of a sudden decline in precipitation drought indexes is higher. There are a number of hotspots. Especially significant are those in various parts of Australia (with the maximum values of the world on the western coast), Iran, Pakistan, India, Bangladesh, the shores of the Mediterranean, the Southern African Development Community countries, southern Chile and Argentina and northern Mexico. Precipitation is inherently sparse and erratic in some of these areas, so the importance and impacts of the swift occurrence of these anomalies are not necessarily comparable in all of them.

On the other hand, number of areas in western North America, Central Europe, Russia, and China register less extensive clusters.

The total number of identified flash droughts in Fig. 1 clearly depends on the stringency of the thresholds used to 
determine them (from DEPI $>0.4$ to a DEPI of $<0.2$ ). Obviously, if they are loosened there are more identified FDs in general, though the patterns remain similar with the hotspots in precisely the same listed locations (not displayed).

\subsection{Rainfall Characteristics of Flash Drought Prone Areas}

Total annual precipitation, variability of the precipitation (coefficient of variation) for the twelve months of the year, persistence of monthly precipitation, monthly anomaly (precipitation minus the median of the month) autocorrelation from 1 to 4 months' lag and precipitation concentration index have been calculated for each pixel of the database to assess whether any of these parameters have any significant connection to the proneness to registering more FDs.

Using the pixels both with and without zero FDs in the total of the series, the only Pearson correlations significantly different from 0 are those with the variability of all the months and with factor combinations of them, but only with $\mathrm{R}$ around 0.3 . The scatterplots' visual analysis did not reveal any interpretable feature. The Spearman correlations show similar features.

The average monthly precipitation regimes were also calculated for all the pixels and groups of them were extracted with cluster analysis. Two different methods were applied to achieve that partition: (1) K-means cluster extraction with the 12 monthly averages expressed in millimeters; and (2) K-means cluster extraction with the percentage of total annual average precipitation that corresponds to each of the 12 months, as a way to rescale the monthly values and also make them representative of their specific contribution to the yearly sum. Scaling (normalizing) the monthly values and monthly percentages for pixel clustering was tried as well, but it produced very similar grouping results to meth- ods 1 and 2, respectively.

$\mathrm{K}$-means was applied to the pixel regimes, with prior exploration of the inside groups' sum of squares by number of clusters extracted to determine the suitable number of clusters. In the two cases, 12 dissimilar rainfall behaviors grouped all the land pixels with sufficient internal cohesion.

The number of registered FDs was compared among the 12 precipitation regimes, for their two different classifications. After applying the Shapiro-Wilk test and analyzing the plots of residuals, the data cannot be considered to be normally distributed, nor can it be assumed that the variance across groups is homogeneous. The Welch one-way test and Pairwise t-tests with no assumption of equal variances, plus the Kruskal-Wallis rank sum test, were applied to check whether there are differences between the groups in the ways they experience FDs. Table 1 and Fig. 2 summarize the main results.

The results in Fig. 2 and Table 1 confirm that FDs do not show similar occurrence across the different rainfall patterns. Semi-arid to arid regimes that receive almost all of their precipitation during certain seasons are prone to recording more FDs, while humid regimes show fewer. On the other hand, the boxplot in the lower part of Fig. 2 suggests that more regular regimes tend to experience fewer FDs; however, regime type 7 is the only one with significantly fewer FDs. This is in agreement with the sharp declines, with less soil moisture, found by Koster et al. (2019) in the year-round wet areas of the world, even though their hypothesis assigns more importance to the fact that the overall humid conditions do not allow for those episodes, while we will explain in the coming sections that this may have more to do with precipitation regularity than abundance.

However, some of the regime types do not have enough cases for statistically significant comparison, so further specific research is needed to substantiate these findings.

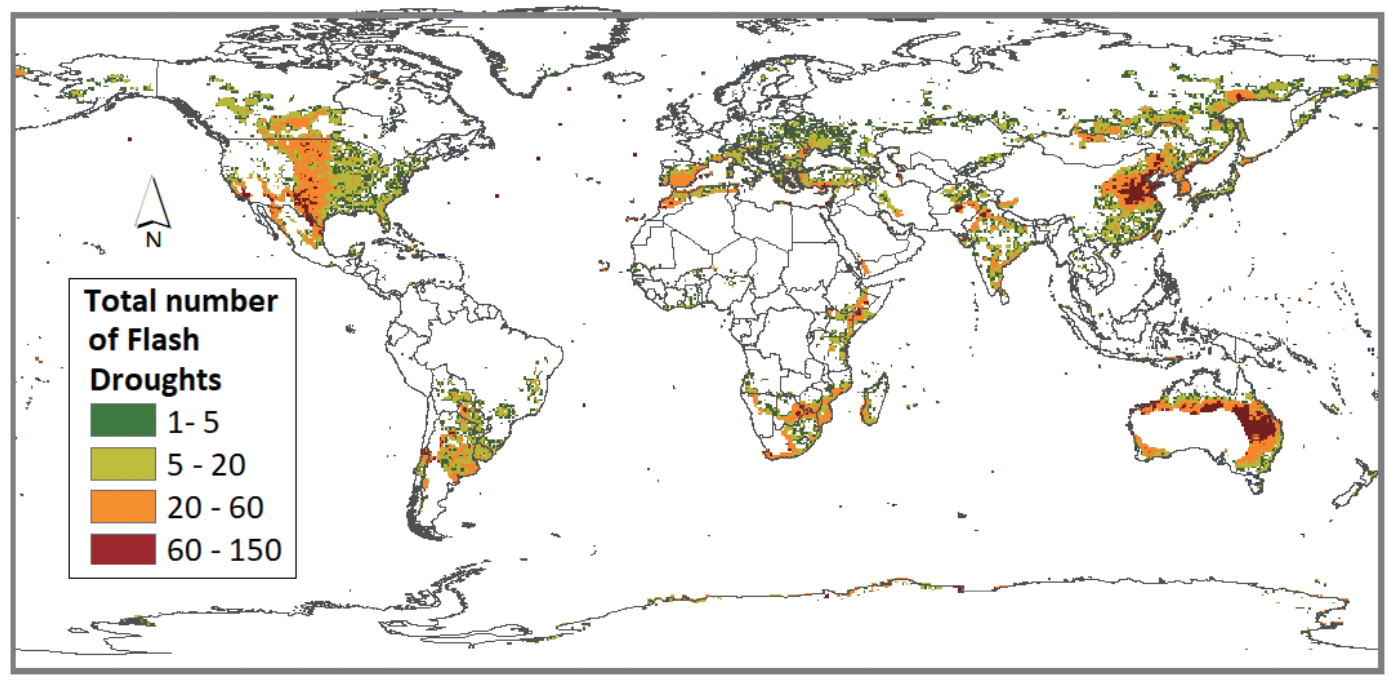

Fig. 1. Number of precipitation-deficit flash droughts per pixel from 1979 to 2020 . CPC precipitation dataset. 
Table 1. Results of the tests applied to assess similarity in the occurrence of flash droughts in the different rainfall regimes, using two different clustering methods. See Fig. 2 for their graphic depiction.

\begin{tabular}{|c|c|c|c|c|}
\hline Clustering method & Welch one-way test & Pairwise comparison t-test & Kruskal-Wallis rank sum test & Interpretation and observations \\
\hline \multirow{2}{*}{$\begin{array}{l}\text { (1) Extraction with the } \\
12 \text { monthly averages } \\
\text { expressed in millime- } \\
\text { ters }\end{array}$} & $\begin{array}{c}\text { Including the pixels with } \\
\text { zero FDs: } \mathrm{F}=57.926, \\
\text { num } \mathrm{df}=11, \text { denom } \mathrm{df}= \\
12049, \mathrm{p} \text {-value }<2.2 \mathrm{e}-16\end{array}$ & $\begin{array}{c}\text { Including the pixels with zero } \\
\text { FDs, there are significant } \\
\text { differences ( } p \text { values below } \\
\text { 0,001) in: } \\
\text { Regime } 12 \text { - Regime } 10 \\
\text { Regime } 12 \text { - Regime } 4 \\
\text { Regime } 4 \text { - Regime } 3 \\
\text { Regime } 5 \text { - Regime } 3 \\
\text { Regime } 6 \text { - Regime } 10 \\
\text { Regime } 6 \text { - Regime } 11 \\
\text { Regime } 6 \text { - Regime } 12 \\
\text { Regime } 6 \text { - Regime } 5 \\
\text { Regime } 8 \text { with all } \\
\end{array}$ & $\begin{array}{l}\text { Including the pixels with zero } \\
\text { FDs: } \mathrm{K}-\mathrm{W} \text { chi-squared }=1497 \text {, } \\
\text { df }=11, \mathrm{p} \text {-value }<2.2 \mathrm{e}-16\end{array}$ & \multirow{2}{*}{$\begin{array}{l}\text { P values are close to } 0 \text {. The } \\
\text { regimes' groups are significantly } \\
\text { different with respect to the num- } \\
\text { ber of FDs experienced during the } \\
\text { period 1901- 2019. Drier regimes } \\
\text { with seasonality show more FD } \\
\text { cases. There are few FD cases in } \\
\text { equatorial rainfall regimes }\end{array}$} \\
\hline & $\begin{array}{c}\text { Without the pixels with } \\
\text { zero FDs: } \mathrm{F}=27.947, \\
\text { num } \mathrm{df}=11.00, \text { denom } \\
\mathrm{df}=233.65, \mathrm{p} \text {-value }< \\
2.2 \mathrm{e}-16\end{array}$ & $\begin{array}{c}\text { Without the pixels with zero } \\
\text { FDs, there are significant } \\
\text { differences in: } \\
\text { Regime } 3 \text { - Regime } 10 \\
\text { Regime } 3 \text { - Regime } 11 \\
\text { Regime } 3 \text { - Regime } 12 \\
\text { Regime } 6 \text { - Regime } 10 \\
\text { Regime } 6 \text { - Regime } 11 \\
\text { Regime } 6 \text { - Regime } 4 \\
\text { Regime } 6 \text { - Regime } 5 \\
\text { Regime } 8 \text { with all }\end{array}$ & $\begin{array}{c}\text { Without the pixels with zero } \\
F D \text { : } \mathrm{K}-\mathrm{W} \text { chi-squared }= \\
158.87, \mathrm{df}=11, \mathrm{p} \text {-value }< \\
2.2 \mathrm{e}-16\end{array}$ & \\
\hline \multirow[t]{2}{*}{$\begin{array}{l}\text { (2) Extraction with the } \\
\text { percentage of total an- } \\
\text { nual average precipita- } \\
\text { tion that corresponds to } \\
\text { each of the } 12 \text { months }\end{array}$} & $\begin{array}{l}\text { Including the pixels with } \\
\text { zero FDs: } \\
\qquad \begin{array}{c}\mathrm{F}=39.672, \text { num } \mathrm{df}= \\
11, \text { denom } \mathrm{df}=11042 \\
\text { p-value }<2.2 \mathrm{e}-16\end{array}\end{array}$ & $\begin{array}{c}\text { Including the pixels with zero } \\
\text { FDs, there are significant } \\
\text { differences in: } \\
\text { Regime } 2 \text { - Regime } 10 \\
\text { Regime } 2 \text { - Regime } 11 \\
\text { Regime } 3 \text { - Regime } 1 \\
\text { Regime } 3 \text { - Regime } 10 \\
\text { Regime } 3 \text { - Regime } 11 \\
\text { Regime } 3 \text { - Regime } 2 \\
\text { Regime } 8 \text { - Regime } 7 \\
\text { Regime } 8 \text { - Regime } 1 \\
\text { Regime } 8 \text { - Regime } 10 \\
\text { Regime } 8 \text { - Regime } 11 \\
\text { Regime } 8 \text { - Regime } 3 \\
\text { Regime } 7 \text { - Regime } 1 \\
\text { Regime } 7 \text { - Regime } 10 \\
\text { Regime } 7 \text { - Regime } 11 \\
\text { Regime } 7 \text { - Regime } 2 \\
\text { Regime } 6 \text { - Regime } 1 \\
\text { Regime } 6 \text { - Regime } 10 \\
\text { Regime } 6 \text { - Regime } 11 \\
\text { Regime } 12,4 \text {, and } 5 \text { are only } \\
\text { similar among themselves } \\
\end{array}$ & $\begin{array}{l}\mathrm{K}-\mathrm{W} \text { chi-squared }=1540.6, \mathrm{df} \\
\quad=11, \mathrm{p} \text {-value }<2.2 \mathrm{e}-16\end{array}$ & \multirow[t]{2}{*}{$\begin{array}{l}\text { P values are close to } 0 \text {. The } \\
\text { regimes' groups are significantly } \\
\text { different with respect to the num- } \\
\text { ber of FDs experienced during the } \\
\text { period 1901- 2019. More irregular } \\
\text { regimes frequently show more } \\
\text { FDs in their series }\end{array}$} \\
\hline & $\begin{array}{c}\text { Without the pixels with } \\
\text { zero FDs } \\
\mathrm{F}=12.177, \text { num } \mathrm{df}= \\
\begin{array}{c}11.00, \text { denom } \mathrm{df}=341.28 \\
\text { p-value }<2.2 \mathrm{e}-16\end{array}\end{array}$ & $\begin{array}{c}\text { Without the pixels with zero } \\
\text { FDs, there are significant } \\
\text { differences in: } \\
\text { Regime } 2 \text { - Regime } 11 \\
\text { Regime } 3 \text { - Regime } 11 \\
\text { Regime } 3 \text { - Regime } 12 \\
\text { Regime } 4 \text { - Regime } 11 \\
\text { Regime } 4 \text { - Regime } 12 \\
\text { Regime } 5 \text { - Regime } 11 \\
\text { Regime } 5 \text { - Regime } 12 \\
\text { Regime } 7 \text { - Regime } 3 \\
\text { Regime } 7 \text { - Regime } 4 \\
\text { Regime } 7 \text { - Regime } 5 \\
\text { Regime } 8 \text { - Regime } 11 \\
\text { Regime } 8 \text { - Regime } 7\end{array}$ & $\begin{array}{l}\mathrm{K}-\mathrm{W} \text { chi-squared }=38.212, \mathrm{df} \\
=11, \mathrm{p} \text {-value }=7.206 \mathrm{e}-05\end{array}$ & \\
\hline
\end{tabular}



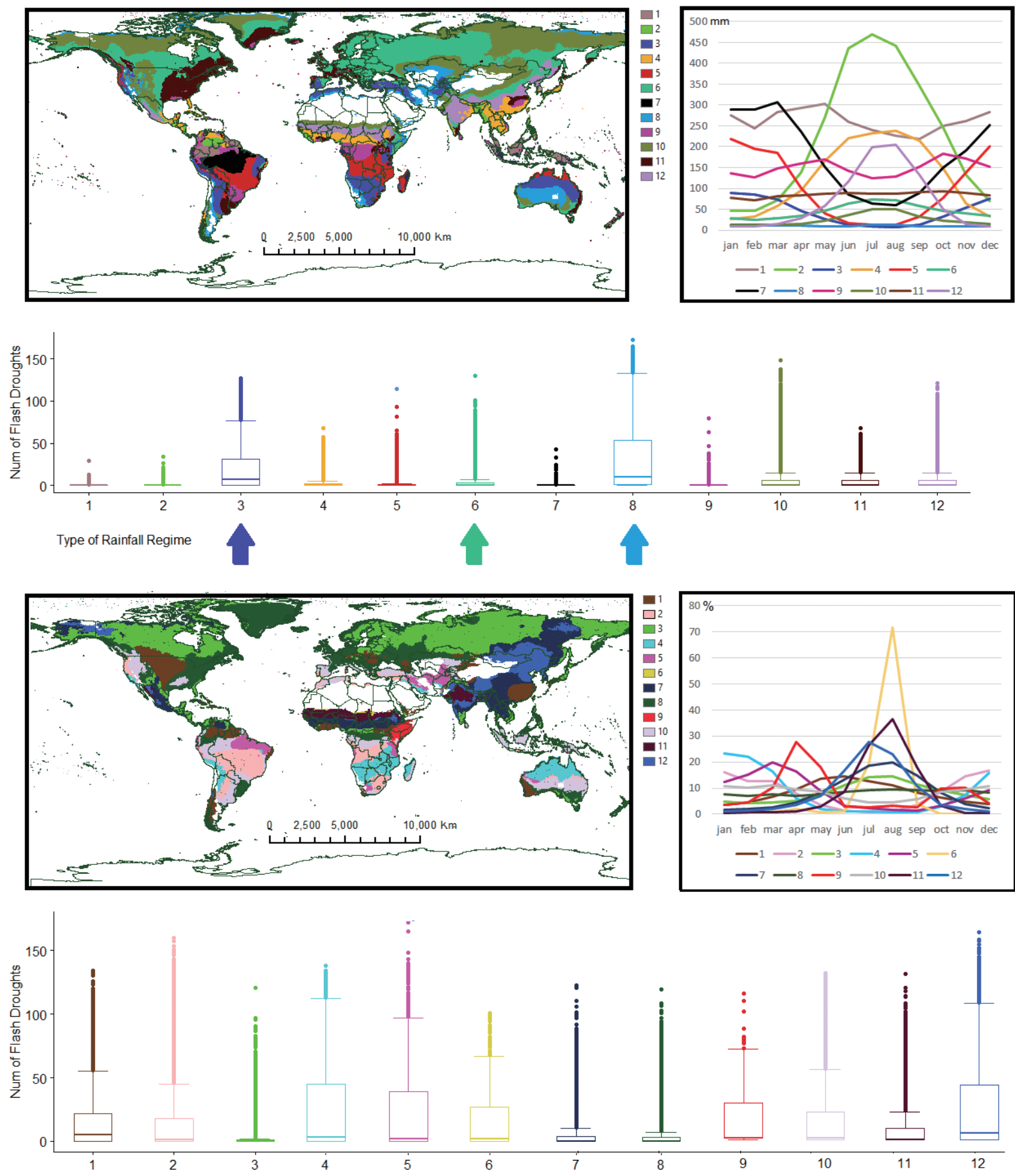

Type of Rainfall Regime

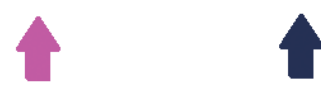

Fig. 2. Boxplots displaying the occurrence of flash droughts in the different rainfall regimes, using two different clustering methods: (1) (Up) Extraction with the 12 monthly averages expressed in millimeters, (2) (Down) Extraction with the percentage of total annual average precipitation that corresponds to each of the 12 months. The arrows mark the regimes that are significantly different to the rest, in agreement with Table 1 . 


\subsection{Incidence of Flash Droughts Within the Year}

For each of the pixels, the ten highest pentad rainfall averages of the climograph have been identified and the percentage of the total number of FDs occurring in those ten pentads calculated. The results are depicted in Fig. 3.

As the figure shows, the great majority of the areas recording FDs suffered most of them during a peak precipitation time of the year in their local regimes, except the south of Australia and the coasts of the US and Argentina. This is very logical if we consider the formulation of the DEPI drought index and, in particular, the definition of anomaly on which it is based: a departure from the median of the pentad. Pentads in wet months have larger medians and that can result in an occasional, sharp and bulk negative anomaly if there is little rain. But this is only possible if in that particular place the variability of the rainfall of that wet month (and pentad) allows for it. This is in agreement with the significant correlation between the total number of FDs in a pixel and the variability of some of the months within it.

Such is the case of the monsoon regions, but also of other areas of the world with erratic rainfall generation mechanisms like the Mediterranean climates. It is important to note that when the onset of some of these rainfall mechanisms is delayed with respect to the average situation, even if the final total quantities in the season end up matching the normal ones, the methodology used will record an FD in the expected onset pentad if the deficit is severe enough. This is a positive aspect, considering that the moisture deficit in the system can cause a stress that does not necessarily recover totally if compensated later, as has been studied for monsoon (Bhuiyan and Kogan 2010) and subtropical (Bodner et al. 2015) vegetation.

At the same time, those anomalies in the wettest times of the year will be more exceptional if the rest of the time it is not frequent to register large ones (because the other parts of the year are drier or more regular), which explains why more irregular (seasonal) climates with intra-annual precipitation variability are more prone to developing FDs. This characteristic of a certain climate also explains its capacity to pass from normality to a considerable drought condition in a short time.

Theoretically, if a large anomaly is more frequent in wet pentads, it should be rated as less exceptional, but considering its potential repercussion in a system that expects significant rainfall in those particular pentads and not so much in other pentads, it should not be contemplated as a statistical bias ${ }^{1}$ but rather as a useful approach to indicating a real, fast and intense threat to water availability. The monthly frequency of FDs measured with soil moisture per- centiles presented by Koster et al. (2019) for the US also points to events in Texas and the Great Plains concentrating in their wettest and warmest months, presumably meaning that the impacts in that variable are more sensitive to bulk rainfall deficits in that part of the year in which the soil usually refills, while anomalies in drier months do not have a rapid and noticeable response.

\subsection{Temporal Evolution of the Incidence of Flash Droughts}

The study period was divided into eight sections, for which the number of FDs recorded per pixel was counted: 1979 - 1985, 1986 - 1990, 1991 - 1995, 1996 - 2000, 2001 2005, 2006 - 2010, 2011 - 2015, 2016 - 2020.

The trends in the number of FDs experienced per pixel during the eight sub-periods were examined. Figure 4 shows only the pixels around the world whose trend line fits significantly, considering a p-value threshold of 0.05 . In general, there are only scattered pixels in which significant trends are observed, towards both more and less frequency of FDs. If the p-value threshold is relaxed, more regional patches appear around the pixels observed in Fig. 4. Only in Yemen, Morocco, the State of Arizona and Australia there are extensive regions with consistent significant (increasing) trends. Studies like Wang et al. (2015) endorse the trend in intensification of the phenomenon in the central US.

\subsection{Comparison of the Observed Manifestation of DEPI Flash Droughts with Methods and Events Studied in Earlier Research}

We have performed a straightforward test of the similitude of the recognition of FD with DEPI and the most used methods, which include other variables: Mo and Lettenmaier $(2015,2016)$ and the Ford and Labosier approach, broadly replicated and adapted. The territory of the United States has been used for the purpose, considering the wealth of hydroclimatic information available and the fact that its territory contains a broad variety of rainfall regimes and different proneness to experience FD, according to the previous chapters and to the mentioned studies.

The Smerge $0.125^{\circ}$ resolution product, developed by merging the North American Land Data Assimilation System (NLDAS) land surface model output, has been used for the daily soil moisture anomalies of the $0-40 \mathrm{~cm}$ layer. The Modern-Era Retrospective analysis for Research and Applications version 2 (MERRA-2) is a NASA atmospheric reanalysis for the satellite era using the Goddard Earth Observing System Model. We used the MERRA-2 2-meter

\footnotetext{
1 Also, the same issue of comparison (or combination) of time intervals of different nature appears for some of the multivariable indexes used in other papers. For example, Yuan et al. (2019) or Li et al. (2020a) detect FDs by observing and comparing sudden drops in soil moisture, temperature and/or precipitation, regardless of the time of the year in which they occur.
} 


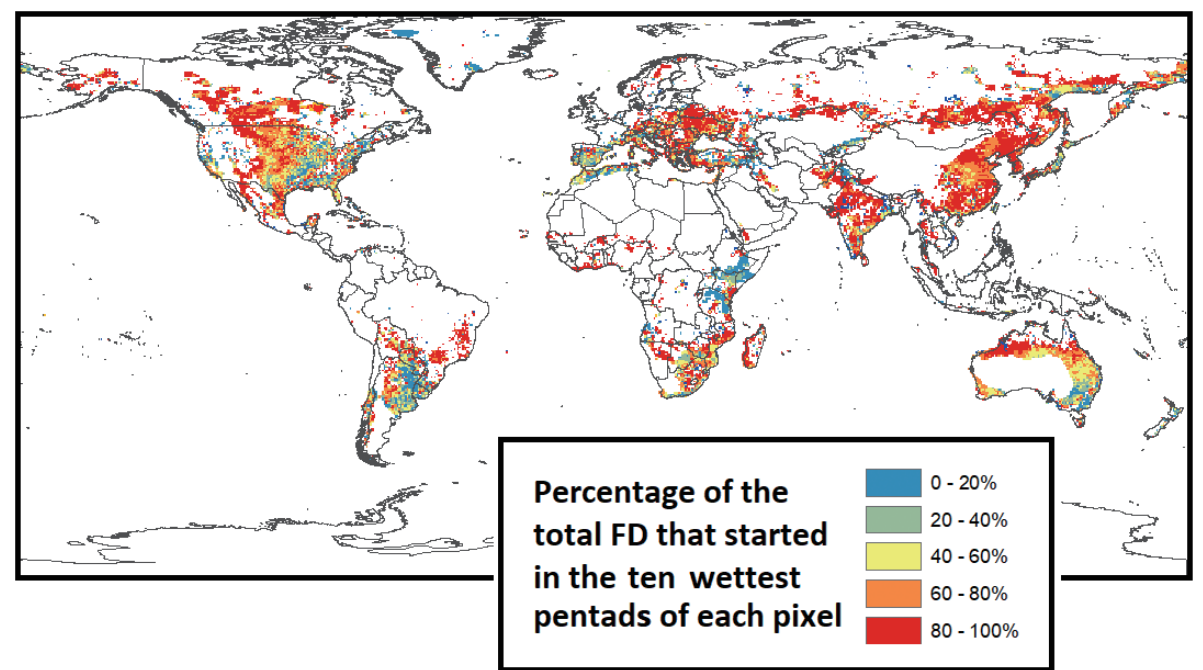

Fig. 3. Percentage of total flash droughts that occurred in one of the ten pentads of highest average precipitation in each of the pixels with one or more events.

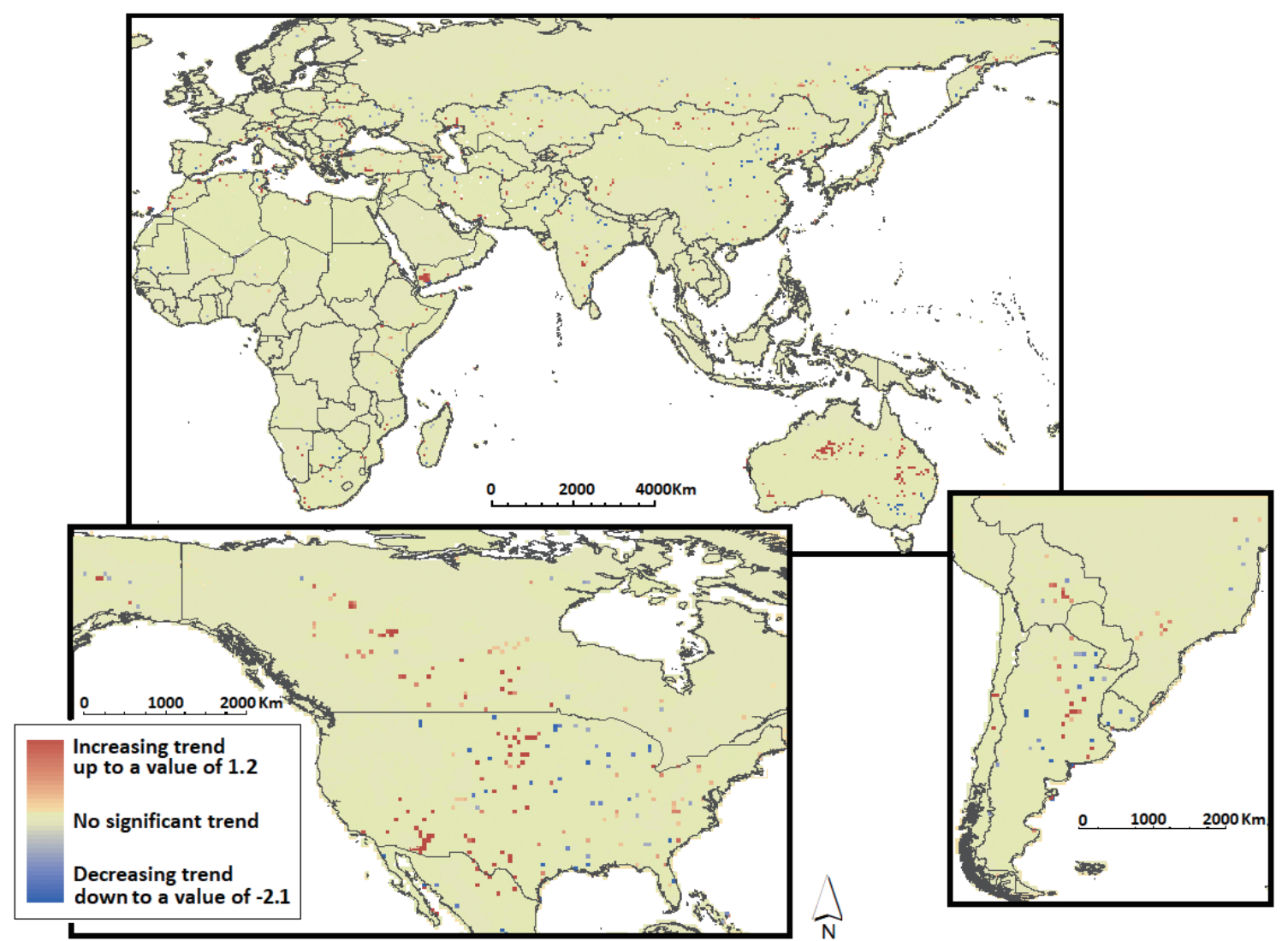

Fig. 4. Significant increasing (red) and decreasing (blue) trends in precipitation-deficit FD incidence during the study period 1979 - 2020 . Beige pixels are desert areas, do not have FDs or do not show a significant trend. 
air temperature daily means at a spatial resolution of $0.5^{\circ}$ $\times 0.625$. Last, the evapotranspiration daily values were obtained from the NASA Global Land Data Assimilation System Version 2 (GLDAS-2), offered at a resolution of $0.25^{\circ}$.

The indices explained in literature were applied to the series aggregated by pentads and the temporal coincidence in the identified FD has been measured. Table 2 shows a sample of the results for seven points throughout the US, both for the comparison of occurrence pentad by pentad (labeled as "no lag") and for the comparison of each pentad in the DEPI with the same and the following pentad in the other indices (labeled as "including the following pentad").

The two first blocks of rows show two similar approaches by the same authors. Since the second approach (Mo and Lettenmaier 2016) is focused on precipitation deficit-related FD, it recognizes situations in which evapotranspiration and precipitation are anomalously low and the match with the events identified with DEPI is very significant, with the exception that the DEPI methodology is more restrictive and marks less events.

The opposite situation is observed with the Ford and Labosier methodology, which marks few FD because of its strict criteria: soil moisture needs to pass quickly from normality to below the $20^{\text {th }}$ percentile. A $79 \%$ of the FDs by Ford and Labosier events not captured by the method presented in this paper occur in rainfall drought moments (when DEPI is low), but not exactly at the same time as the DEPI index marks a drought swift intensification. Other variables clearly play a role in the events that are not identified, which confirms the need to distinguish between precipitation deficit FD and heat-wave FD.

It is observed that the coincidence increases significantly when we compare also with the subsequent pentad of the series of FD of the other indices, namely the DEPI FDs often occur around a pentad before the FDs are identified with other methods.

The rainfall regimes plotted in yellow (4), found in Florida for this example, show significantly less connection between methods. In these cases, the relationship between the entire series of precipitation anomalies or precipitation indices like the DEPI and the other relevant variables for the definition of FD are less strong (see Table 3), indicating that a lack of rainfall does not induce the same swift disturbance in soil moisture or evapotranspiration. These rainfall regimes are found in tropical areas, where the humid season coincides with the warm season and in which rainfall drought and drought in the soil are not so concomitant.

The same table shows that the DEPI index has close connection with the evolution of soil moisture in the studied regimes, beyond what is already captured by the rainfall anomalies, especially when a lag of one time step is added in the correlation calculation. This reveals that the particular temporal accumulation in the calculation of DEPI makes it suitable to understand better the moisture circumstances, even if its swift declines are not always followed by rapid declines in the soil water.

Apart from this exercise, the description of FD occurrence in other studies has been compared to the results of this research.

The analysis conducted by Noguera et al. (2020) with the SPEI scale 1 index for Spain revealed many more FD events in a slightly longer study period (in their case 1961 2018), compared to this one, due to the fact that their index (SPEI-1) fluctuates much more, as unlike the DEPI it does not consider previous water deficit or surplus conditions. However, the distribution patterns of the areas in which this phenomenon is becoming more prominent and the temporal trends they register (significant decrease of the number of events in the same pixels inland, increase in the south and on the Mediterranean coast) considerably match the results obtained here. Since the SPEI takes evapotranspiration into account, if there were FD events triggered largely by an anomaly in that variable, these would not be identified with DEPI, which might explain why higher concordance between the two studies was not found.

Chen et al. (2019) examined the development of five selected flash droughts. Despite the fact that these events are pinpointed using the US Drought Monitor combined drought indicators (incorporating the Palmer Index, Soil Moisture levels, streamflow percentiles, and the Standardized Precipitation Index), our analysis recognized the five of them: 2000, 2003, 2006, 2007, and 2012 flash droughts in the mentioned months and areas of the country. The fact that other hydrological variables are used in Chen et al. (2019) does not add too much discrepancy in this case.

Wang et al. (2015) documented a rapid drought intensification from June to July 2012 in the Central U.S., as part of a trend of more difference in rainfall between both months in the region. This DEPI analysis found that the last pentad of June or the first of July 2012 registered FD in most of the pixels of Texas and the east of Colorado, on the one hand, and around the state of North Dakota, on the other hand, as the geographical cores of the precipitation phenomenon.

Koster et al. (2019) provide the geographical coordinates of a point in Oklahoma for which the 2000 summer flash drought is described in detail. The event evolution is captured with the DEPI in the same cell. Apart from that, their Figs. 5, 6, and 9 show patterns in the number of flash droughts that correspond with those in our Fig. 1.

In the paper by Li et al. (2020a), the authors recognize and describe a series of 24 flash droughts in China's Pearl River Basin, using the behavior of the evaporation deficit, namely the difference between actual and potential evapotranspiration. Twenty of the FDs they identify are detected in different parts of the basin at the same time with the method presented here, while the other listed droughts are marked by the DEPI, though not with the intensity or the quick intensification required to qualify as an FD. 


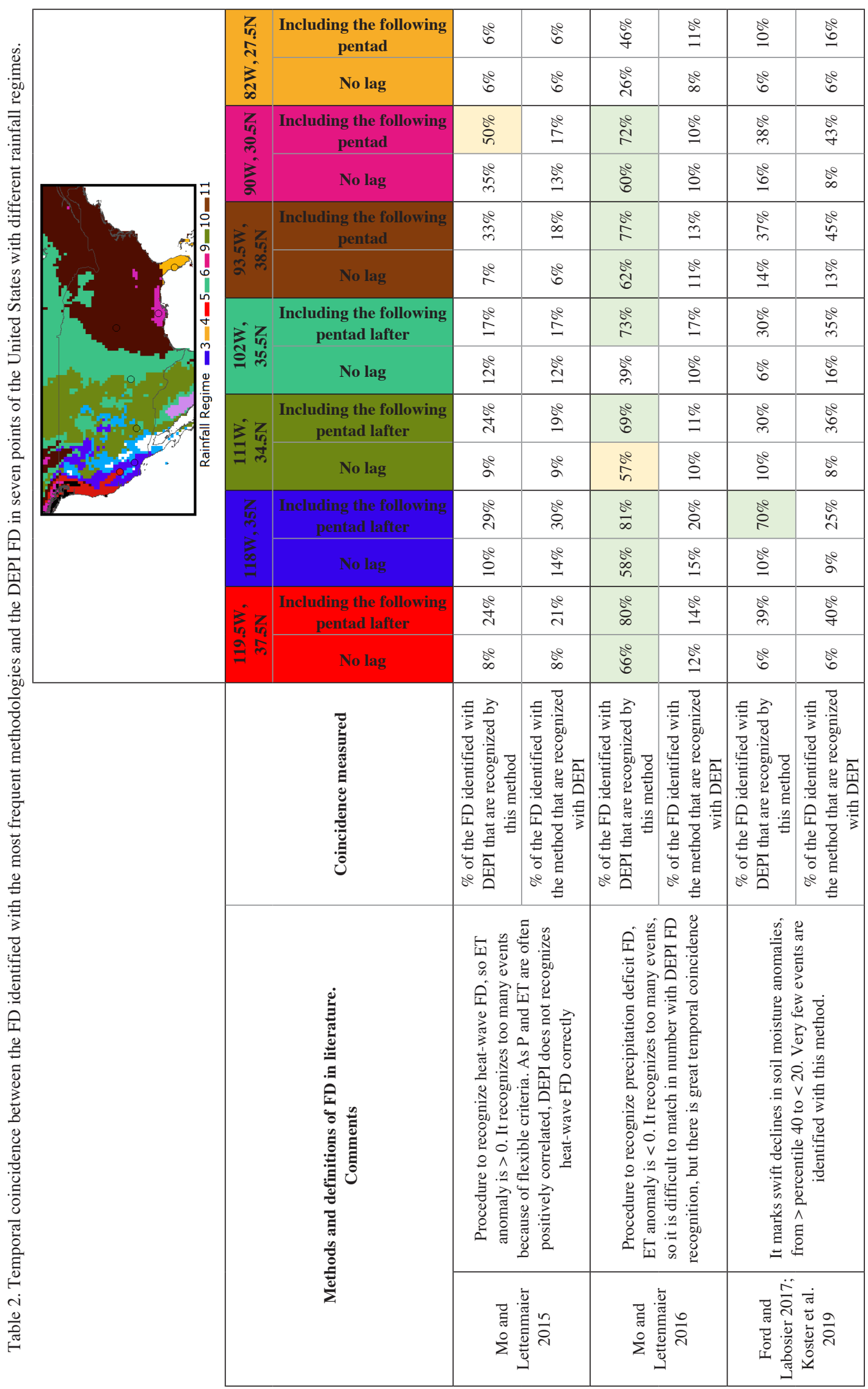


Table 3. Correlation between the DEPI temporal series and the series of anomalies in the variables considered in other FD studies, compared to the correlation with the evolution of rainfall anomalies in seven points of the United States.

\begin{tabular}{|c|c|c|c|c|c|c|c|c|c|c|c|c|c|c|}
\hline \multirow[b]{2}{*}{ Pearson correlation of the pentad series } & \multicolumn{2}{|c|}{$\begin{array}{c}119.5 \mathrm{~W} \\
37.5 \mathrm{~N}\end{array}$} & \multicolumn{2}{|c|}{$118 \mathrm{~W}, 35 \mathrm{I}$} & \multicolumn{2}{|c|}{$\begin{array}{l}111 \mathrm{~W} \\
34.5 \mathrm{~N}\end{array}$} & \multicolumn{2}{|c|}{$\begin{array}{l}102 \mathrm{~W}, \\
35.5 \mathrm{~N}\end{array}$} & \multicolumn{2}{|c|}{$\begin{array}{c}93.5 \mathrm{~W} \\
38.5 \mathrm{~N} \\
\end{array}$} & \multicolumn{2}{|c|}{$90 \mathrm{~W}, 30.5 \mathrm{~N}$} & \multicolumn{2}{|c|}{$82 \mathrm{~W}, 27.5 \mathrm{~N}$} \\
\hline & $\frac{z}{0}$ & 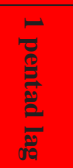 & & & $\frac{Z}{3}$ & 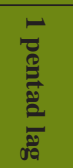 & 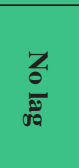 & 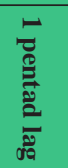 & $\frac{Z}{3}$ & 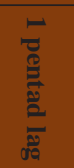 & $\frac{Z}{0}$ & 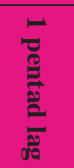 & $\frac{Z}{0}$ & 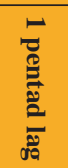 \\
\hline DEPI vs Soil moisture anomalies & 0,36 & 0,45 & 0,29 & 0,42 & 0,45 & 0,53 & 0,5 & 0,57 & 0,5 & 0,55 & 0,55 & 0,43 & 0,25 & 0,25 \\
\hline DEPI vs Temperature anomalies & $-0,5$ & $-0,37$ & $-0,36$ & $-0,23$ & $-0,41$ & 0,08 & $-0,45$ & $-0,3$ & $-0,21$ & $-0,3$ & $-0,21$ & $-0,27$ & $-0,11$ & $-0,12$ \\
\hline DEPI vs Evapotranspiration anomalies & 0,37 & 0,47 & 0,33 & 0,4 & 0,37 & 0,45 & 0,41 & 0,56 & 0,39 & 0,2 & 0,46 & 0,1 & 0,18 & 0,11 \\
\hline $\mathrm{P}$ anomalies vs Soil moisture anomalies & 0,19 & 0,3 & 0,22 & 0,28 & 0,21 & 0,28 & 0,24 & 0,33 & 0,22 & 0,32 & 0,31 & 0,33 & 0,16 & 0,2 \\
\hline $\mathrm{P}$ anomalies vs Temperature anomalies & $-0,26$ & $-0,26$ & $-0,17$ & $-0,13$ & $-0,19$ & $-0,22$ & $-0,25$ & $-0,3$ & $-0,04$ & $-0,22$ & $-0,06$ & $-0,17$ & $-0,27$ & $-0,3$ \\
\hline $\mathrm{P}$ anomalies vs Evapotranspiration anomalies & 0,12 & 0,15 & 0,12 & 0,21 & 0,11 & 0,25 & 0,23 & 0,35 & 0,43 & 0,14 & 0,5 & 0,2 & 0,2 & 0,06 \\
\hline
\end{tabular}

Moreover, their second paper (Li et al. 2020b) states that precipitation deficit flash drought largely occurred in the western Pearl River Basin during the historical period, which coincides fully with the results presented in Fig. 1.

Finally, Nguyen et al. (2019) describe the evolution of several hydrometeorological variables in two consecutive FDs in the Murray Darling Basin of Australia, in the beginning of 2018 and of 2019. The first one is perfectly noticeable with the DEPI, though after its onset the deficit is sustained for months, during which the DEPI did not recover from a moderate drought state. What can therefore be perceived in the DEPI for January 2019 is a sharp decline from this modest recuperation, leading to worst drought circumstances of the entire series. It is also marked as a FD. However, the fact that the index used considers the accumulation of the previous conditions, allows to interpret this second drought almost as a rapid and deep intensification of an already established drought, instead of a totally new FD which emerges.

\section{SUMMARY AND CONCLUSIONS}

The notion of flash drought and the analysis of the respective hazard only developed recently, upon verification that even a short episode with rapid drought intensification was capable of producing disruption and losses. Globalscale spatiotemporal patterns and proneness to experiencing intense and rapid deficits of the core variables participating in the phenomenon have nevertheless not yet drawn much attention.

In this analysis, we use an uncomplicated framework to characterize historical precipitation-deficit flash drought events at global scale, based exclusively on identifying sudden drops in the series of the DEPI rainfall drought index. We studied flash drought characteristics using CPC Global Unified Gauge-Based Analysis of Daily Precipitation data from 1979 to 2020 , the aim being to learn how the purely rainfall phenomenon develops and to confirm whether it is possible to recognize the events identified with the use of several variables and their particularities if only precipitation at pentad temporal resolution is considered.

Most preceding studies use complex modelling and indexes which rely on data that is not easy to find in all environments and would make a global or a long-term characterization like the one done here more challenging.

In this regard, the DEPI index presents advantages for characterizing rainfall-related flash droughts:

(1) Its computational simplicity, because it includes definition, accumulation and standardization of rainfall anomalies in just one figure per pentad, obtained in three simple stages. The detection of a flash drought is completed by comparing successive pentad values and checking if the declines are sharp enough, from above the $40^{\text {th }}$ percentile (DEPI $>0.4$ ) to below the $20^{\text {th }}$ percentile (DEPI $<0.2$ ).

(2) Its drought onset and intensity recognition capacity. The DEPI calculation method restarts the accumulation of anomalies every time precipitation below the pentad median is found after a period of surplus accumulation; in the following stage, all the cumulative anomalies calculated are normalized using plotting positions (equivalent to percentiles), so that only the truly exceptional ones are marked as drought (DEPI $<0.5$, half of the series of cumulative anomalies, the rest is wet). Therefore, only $20 \%$ of the values of cumulative anomalies in an entire series have DEPI values below $<0.2$ intensity, usually after some pentads of deficit accumulation. That implies that only great sudden deficits after a surplus can fall below the $20^{\text {th }}$ percentile of cumulative anomalies in just a single pentad and be defined as a flash drought under the method used, guaranteeing that the few events recognized are indeed extraordinary. It is a more restrictive recognition approach than those found in other studies, so it will be essential to validate the thresholds used in forthcoming research. 
On the other hand, with DEPI, the accumulation does not end or restart if the deficit continues over the course of pentads, so the same drought sequence can become gradually more intense without an imposed limit. Indexes that do not consider enough temporal accumulation in their formulation (like those used in most flash drought identification studies to date) will recognize any new intense drop as a new flash drought, while with the DEPI it will be marked as just a growth in severity within the same drought event. The DEPI can therefore help distinguish between a new flash drought and an intensification of an existing drought.

(3) Its suitability for application to different climates, regardless of the magnitude of their precipitation totals, allowing for the study and comparison of droughts (and flash droughts) around the world. This is only possible if standardized or normalized indexes are used.

One of the study's main contributions is the confirmation that there are dominant seasons and areas for flash droughts to arise, mostly in the local humid seasons and in climates with variable precipitation, both inter-annual and intra-annual (seasonal regimes), especially when that variability is significant in the wet parts of the year due to irregular precipitation generation mechanisms. This effect is supported by the DEPI formulation: before normalization, its accumulation adds up all anomalies together, coming from all types of pentads, drier ones and wetter ones. However, very variable wet pentads can have larger positive and negative anomalies than dry ones and are consequently more likely to produce sharp declines and flash droughts. It is useful that those fast anomalies are highlighted because they appear at the same time as flash droughts detected using edaphic-based characterizations methods, indicating that missing substantial precipitation in one of the few times of the year in which a significant amount is expected is potentially harmful for soil moisture and vegetation.

Related to the above, despite other studies pointing to evapotranspiration as the driver for magnification of flash drought conditions, the results obtained also indicate a relevant role played by intensification of the precipitation deficit, given that many of the events identified with the SPEI, evaporative deficit or soil moisture are recognized by simply using a precipitation index. However, the fraction of the events triggered or amplified by sudden temperature anomalies is not recognized with this method.

As pointed out by other authors ( $\mathrm{Li}$ et al. 2020a) and mentioned above, the most recurrent intensification thresholds used in FD literature are empirical and need to be further tested, both in terms of comparing the results of using other levels with what was obtained with the current ones (from above the $40^{\text {th }}$ percentile to below the $20^{\text {th }}$ ), and in terms of confirming when a flash drought produces actual impacts on the ground. When comparing the events recognized in other regional studies with the intensification perceived with the DEPI in the corresponding pixels at the same time, it was found that more than $85 \%$ of the discrepancies corresponded to drought events that were close to being catalogued as flash drought but were not classified as such because of the strict limits established.

Finally, the pentad scale is confirmed as being suitable for providing a sense of past events' spatial distribution and overall behavior and is sufficient for the delivery of periodic retrospective outlooks. The method could be applied to daily, near real time precipitation data to track the onset of new FDs.

The study was unable to confirm remarkable patterns of temporal evolution or trends in the number of flash droughts experienced.

Further research will focus on the application of an index modification that includes proxies for hydrological budgets such as atmospheric evaporative demands, an effort nowadays possible thanks to new global datasets of modelled data like GLEAM or MERRA-2. As with the Standardized Evapotranspiration Deficit Index or the SPEI indexes, the inclusion of these variables will bring different perspectives about the quantification of flash droughts, incorporating those events that are boosted by heat waves with anomalously high evapotraspiration (Noguera et al. 2020). Moreover, other globally modeled variables will be explored both for definition of events and to more thoroughly verify in detail the propagation of a meteorological flash drought to soil moisture, as begun by Koster et al. (2019). The comparison of results with those in this paper will expand the knowledge on where, when and why precipitation plays a more dominant role in flash droughts' materialization and severity than temperatures and evapotranspiration, and vice versa.

Also, it is essential to compare specific flash droughts with observed anomalies in the Normalized Difference Vegetation Index (NDVI), the Vegetation Condition Index, or similar, to assess the vegetation response to this variety of drought and the differences observed regarding the impacts caused by slow-onset conventional droughts. Impacts in other stages of the hydrological cycle are worth confirming as well.

Finally, it is important to perform a detailed analysis of the clusters in which the phenomenon is becoming more prominent in order to understand its implications.

\section{REFERENCES}

Asadi Zarch, M. A., H. Malekinezhad, M. H. Mobin, M. T. Dastorani, and M. R. Kousari, 2011: Drought Monitoring by Reconnaissance Drought Index (RDI) in Iran. Water Resour. Manag., 25, 3485-3504, doi: 10.1007/ s11269-011-9867-1. [Link]

Bhuiyan, C. and F. N. Kogan, 2010: Monsoon variation and vegetative drought patterns in the Luni Basin in the rain-shadow zone. Int. J. Remote Sens., 31, 3223-3242, 
doi: 10.1080/01431160903159332. [Link]

Bodner, G., A. Nakhforoosh, and H.-P. Kaul, 2015: Management of crop water under drought: A review. Agron. Sustain. Dev., 35, 401-442, doi: 10.1007/s13593-0150283-4. [Link]

Chen, M., W. Shi, P. Xie, V. B. S. Silva, V. E. Kousky, R. Wayne Higgins, and J. E. Janowiak, 2008: Assessing objective techniques for gauge-based analyses of global daily precipitation. J. Geophys. Res., 113, doi: 10.1029/2007jd009132. [Link]

Chen, L. G., J. Gottschalck, A. Hartman, D. Miskus, R. Tinker, and A. Artusa, 2019: Flash Droughts Characteristics and Prediction. Atmosphere, 10, 498.

Christian, J. I., J. B. Basara, J. A. Otkin, E. D. Hunt, R. A. Wakefield, P. X. Flanagan, and X. Xiao, 2019: A methodology for flash drought identification: Application of flash drought frequency across the United States. J. Hydrometeorol., 20, 833-846, doi: 10.1175/ jhm-d-18-0198.1. [Link]

Ford, T. W. and C. F. Labosier, 2017: Meteorological conditions associated with the onset of flash drought in the eastern United States. Agric. For. Meteorol., 247, 414423, doi: 10.1016/j.agrformet.2017.08.031. [Link]

Koster, R. D., S. D. Schubert, H. Wang, S. P. Mahanama, and A. M. DeAngelis, 2019: Flash drought as captured by reanalysis data: Disentangling the contributions of precipitation deficit and excess evapotranspiration. $J$. Hydrometeorol., 20, 1241-1258, doi: 10.1175/jhmd-18-0242.1. [Link]

Li, J., Z. Wang, X. Wu, J. Chen, S. Guo, and Z. Zhang, 2020a: A new framework for tracking flash drought events in space and time. CATENA, 194, 104763, doi: 10.1016/j.catena.2020.104763. [Link]

Li, J., Z. Wang, X. Wu, S. Guo, and X. Chen, 2020b: Flash droughts in the Pearl River Basin, China: Observed characteristics and future changes. Sci. Total Environ., 707, 136074, doi: 10.1016/j.scitotenv.2019.136074. [Link]

Limones, N., M. F. Pita-López, and J. M. CamarilloNaranjo, 2020: A new index to assess meteorological drought: The Drought Exceedance Probability Index (DEPI). Atmósfera, doi: 10.20937/atm.52870. [Link]

Liu, Y., Y. Zhu, L. Ren, J. Otkin, E. D. Hunt, X. Yang, F. Yuan, and S. Jiang, 2020: Two Different Methods for Flash Drought Identification: Comparison of Their Strengths and Limitations. J. Hydrometeorol., 21, 691704, doi: 10.1175/JHM-D-19-0088.1. [Link]

McKee, T. B., N. J. Doesken, and J. Kleist, 1995: Drought monitoring with multiple time Scales. Proceedings of the 9th Conference on Applied Climatology, American Meteorological Society, Dallas, TX, 233-236.

Mo, K. C. and D. P. Lettenmaier, 2015: Heat wave flash droughts in decline. Geophys. Res. Lett., 42, 28232829, doi: 10.1002/2015gl064018. [Link]
Mo, K. C. and D. P. Lettenmaier, 2016: Precipitation deficit flash droughts over the United States. J. Hydrometeorol., 17, 1169-1184, doi: 10.1175/jhm-d-15-0158.1. [Link]

Nguyen, H., M. C. Wheeler, J. A. Otkin, T. Cowan, A. Frost, and R. Stone, 2019: Using the evaporative stress index to monitor flash drought in Australia. Environ. Res. Lett., 14, 064016, doi: 10.1088/1748-9326/ab2103. [Link]

Noguera, I., F. Domínguez-Castro, and S. M. Vicente-Serrano, 2020: Characteristics and trends of flash droughts in Spain, 1961-2018. Ann. New York Acad. Sci., 1472, 155-172, doi: 10.1111/nyas.14365. [Link]

Otkin, J. A., M. C. Anderson, C. Hain, I. E. Mladenova, J. B. Basara, and M. Svoboda, 2013: Examining rapid onset drought development using the thermal infraredbased evaporative stress index. J. Hydrometeorol., 14, 1057-1074, doi: 10.1175/jhm-d-12-0144.1. [Link]

Otkin, J. A., M. Svoboda, E. D. Hunt, T. W. Ford, M. C. Anderson, C. Hain, and J. B. Basara, 2018: Flash droughts: A review and assessment of the challenges imposed by rapid-onset droughts in the United States. Bull.Amer. Meteorol.Soc., 99, 911-919, doi: 10.1175/ bams-d-17-0149.1. [Link]

Pendergrass, A. G., G. A. Meehl, R. Pulwarty, M. Hobbins, A. Hoell, A. AghaKouchak, C. J. W. Bonfils, A. J. E. Gallant, M. Hoerling, D. Hoffmann, L. Kaatz, F. Lehner, D. Llewellyn, P. Mote, R. B. Neale, J. T. Overpeck, A. Sheffield, K. Stahl, M. Svoboda, M. C. Wheeler, A. W. Wood, and C. A. Woodhouse, 2020: Flash droughts present a new challenge for subseasonal-to-seasonal prediction. Nat. Clim. Change, 10, 191199, doi: 10.1038/s41558-020-0709-0. [Link]

Svoboda, M., D. LeComte, M. Hayes, R. Heim, K. Gleason, J. Angel, B. Rippey, R. Tinker, M. Palecki, D. Stooksbury, D. Miskus, and S. Stephens, 2002: The Drought Monitor. Bull. Amer. Meteorol. Soc., 83, 1181-1190, doi: 10.1175/1520-0477-83.8.1181. [Link]

Van Loon, A. F., 2013: On the propagation of drought: How climate and catchment characteristics influence hydrological drought development and recovery. Ph.D. Thesis, Hydrology and Quantitative Water Management, Wageningen University, Wageningen, NL, 198 pp.

Vicente-Serrano, S. M., S. Beguería, and J. I. López-Moreno, 2010: A multiscalar Drought Index Sensitive to Global Warming: The Standardized Precipitation Evapotranspiration Index. J. Clim., 23, 1696-1718, doi: 10.1175/2009jcli2909.1. [Link]

Wang, L. and X. Yuan, 2018: Two Types of flash drought and Their Connections with Seasonal Drought. $A d v$. Atmos. Sci., 35, 1478-1490, doi: 10.1007/s00376-0188047-0. [Link]

Wang, L., X. Yuan, Z. Xie, P. Wu, and Y. Li, 2016: Increasing flash droughts over China during the recent global 
warming hiatus. Sci. Rep., 6, 30571, doi: 10.1038/ srep30571. [Link]

Wang, S.-Y. S., J. Santanello, H. Wang, D. Barandiaran, R. T. Pinker, S. Schubert, R. R. Gillies, R. Oglesby, K. Hilburn, A. Kilic, and P. Houser, 2015: An intensified seasonal transition in the Central U.S. that enhances summer drought. J. Geophys. Res., 120, 8804-8816, doi: 10.1002/2014JD023013. [Link]

Yan, D., R. Jiang, J. Xie, Y. Zhao, J. Zhu, and J. Liang, 2021: Characteristics and prediction of extreme drought event using LSTM model in Wei River Basin. Terr. Atmos. Ocean. Sci., 32, 261-274, doi: 10.3319/ TAO.2021.02.07.01. [Link]
Yuan, X., L. Wang, and E. F. Wood, 2018: Anthropogenic Intensification of Southern African Flash Droughts as exemplified by the 2015/16 season. Bull. Amer. Meteorol. Soc., 99, S86-S90, doi: 10.1175/bamsd-17-0077.1. [Link]

Yuan, X., L. Wang, P. Wu, P. Ji, J. Sheffield, and M. Zhang, 2019: Anthropogenic shift towards higher risk of flash drought over China. Nat. Comm., 10, 4661, doi: 10.1038/s41467-019-12692-7. [Link]

Zhang, Y., Q. You, C. Chen, and X. Li, 2017: Flash droughts in a typical humid and subtropical basin: A case study in the Gan River Basin, China. J. Hydrol., 551, 162176, doi: 10.1016/j.jhydrol.2017.05.044. [Link] 